\title{
MEAN REVERSION IN MONETARY AGGREGATES IN CHILE
}

\author{
Miguel A. Martin-Valmayor \\ Universidad Francisco de Vitoria and Universidad Complutense de Madrid, Madrid, \\ Spain \\ Luis A. Gil-Alana \\ University of Navarra, Pamplona, Spain and Universidad Francisco de Vitoria, Madrid, \\ Spain \\ Manuel Monge Moreno \\ Universidad Francisco de Vitoria, Madrid, Spain \\ Luis Madariaga Becerra \\ Universidad Finis Terrae, Santiago de Chile, Chile
}

\begin{abstract}
In this paper we examine the statistical properties of the monetary aggregates in Chile in order to know if the time series display mean reverting behavior. For this purpose, we use techniques based on fractional integration. Monthly data of various Chilean monetary aggregates from January 1986 until August 2019 are used, and the results indicate very weak evidence of mean reversion. In fact, this property is only found in the case of the currency on circulation and M1 for some of the series examined; however, for M2 and M3 the results clearly show high persistence with orders of integration substantially higher than 1. Thus, shocks are expected to have a permanent nature in these cases. Another remarkable feature observed in the results is that the level of persistence in the series seems to grow with the amount of the monetary aggregate. In a multivariate context, performing a FCVAR model, evidence of cointegration is found among the monetary aggregates, finding a long run equilibrium relationship between them.
\end{abstract}

Keywords: Fractional integration; FCVAR model; monetary aggregates; Chile.

JEL Classification: E52; C32.

\author{
Corresponding author: Prof. Miguel Ángel Martín Valmayor \\ Universidad Francisco de Vitoria \\ Facultad de Ciencias Jurídicas y Empresariales \\ 28223 Pozuelo de Alarcón (Madrid) \\ Spain \\ Email: miguel.martin@ufv.es
}

\footnotetext{
* Prof. Luis A. Gil-Alana gratefully acknowledges financial support from the MINEIC-AEI-FEDER ECO2017-85503-R project from 'Ministerio de Economía, Industria y Competitividad' (MINEIC), 'Agencia Estatal de Investigación' (AEI) Spain and 'Fondo Europeo de Desarrollo Regional' (FEDER). Prof. Luis A. Gil-Alana, Dr. Miguel A. Martin-Valmayor and Dr. Manuel Monge also acknowledge financial support from internal Projects of the Universidad Francisco de Vitoria.
} 


\section{Introduction}

This paper deals with the analysis of monetary aggregates in Chile, investigating their degree of persistence and resilience to shocks, also studying if they are mean reverting or not. We check these hypotheses by looking at the order of integration of the series, i.e., the number of differences required to render the series stationary $\mathrm{I}(0)$. Thus, if they are $\mathrm{I}(0)$, no differences are required, shocks will have a transitory nature and mean reversion exists. On the other hand, if the series are $\mathrm{I}(1)$, this means that first differences are required, shocks will have a permanent nature and no mean reversion occurs. In such a case, strong policy measures must be implemented to recover the original levels in the series after the shocks.

In a multivariate context, the usage of cointegration techniques to analyze monetary policies has been one of the most popular techniques in recent times. A good reference is the textbook of Serletis (2007) "Demand for money" where there are several examples with different monetary aggregates looking for stationary long-run relationships. Cointegration techniques had also been widely used by IMF studies. Some practical examples of its application in different countries can be found in Nassar (2005) (Madagascar), Nachega (2001) (Cameroon), Kontolemis (2002) (Euro Area), Benali et al. (2006 Not referenced) (Morocco), Jonsson (1999) (South Africa) or Kinda (2011) (Chad).

A first novelty in this research paper is that we do not focus exclusively on $\mathrm{I}(0)$ or I(1) behavior since we allow for fractional integration, i.e., I(d) where d can be a fractional value. Thus, we permit a larger degree of flexibility in the specification of the series. In this context, mean reversion takes places as long as $\mathrm{d}$ is smaller than 1 , and the lower the value of $d$ is, the faster the recovery process after a shock is. Examples of applications of fractional integration in the context of monetary policy and macroeconomic analysis are 
the papers by Nautz and Scheithauer (2011) that explored the relation between the persistence of the policy spread and the monetary policy implementation of a central bank; Hassler et al. (2014) who studied persistence and the effect of shocks in the banking industry or Caporale et al. (2017) studying the bilateral linkages between the central bank policy rates of the US, the Eurozone, Australia, Canada, Japan and the UK, and finding evidence of a high degree of persistence in all cases. More recent examples include Caporale and Gil-Alana (2018) studying the level of persistence in unemployment rates for the African economies and Lovcha and Pérez-Laborda (2019) who analyze the effects of the monetary policy shocks in comparison with traditional VAR models.

The objective of this article is to evaluate the long-term evolution of the Chilean monetary aggregates and to verify if mean reversion occurs as our main hypothesis. Over the past decades Chile has substantially improved the quality of life of its citizens. However as one of the main commodity producers (particularly copper accounting for $89 \%$ of its total mining exports) pricing fluctuations at the end of the commodity boom, has generated a major impact on the economy after 2011, and particularly after 2018 underlined by social clashes. The impact of COVID-19 will be a challenge for this economy. According to an OECD report (2018), in the short term, solid fundamentals, a global outlook for commodity exports and trade, monetary policy easing and a supportive fiscal stance are helping a gradual recovery, however too many adults have weak basic skills, while the excessive reliance on self-employment and short-term contracts and an inefficient training system are hindering productivity growth and well-being.

The impact of monetary policy within the economy and its behavior against external shocks is a very important question to be answered taking into account that several economic reforms are ongoing and are experiencing some opposition by certain 
parts of its society. This is in fact what we want to investigate by analyzing the structure of its monetary aggregates.

\section{A brief history of the Chilean economy, its financial system and further challenges in the shortcoming future}

The late 80 's and early 90's mark a turning point in the Chilean economy as the country's inflation fell from levels of around $30 \%$ to $4.7 \%$ in 1998. The Central Bank of Chile began its period of autonomy after the promulgation of the Constitutional Organic Law, which had regulated until then the policies and actions carried out by this institution. In this context, Article 1 of the Constitutional Organic Law of the Central Bank of Chile establishes that said institution is an autonomous body, of constitutional rank, and Article 3 states that the Central Bank will aim to ensure the stability of the currency and the normal functioning of internal and external payments as in most developed economies.

An important event in the timeline is the crisis of 1998, in which the country faced unfavorable external conditions, which for an open economy with high capital mobility, constitutes an unfavorable economic scenario with regard to growth. According to Guzmán (2018), the Asian crisis, which reached worldwide proportions, reduced capital flows to Chile by a third of what they had been in the period 1990 to 1997 . Also, the terms of trade of the country decreased by $12.5 \%$ in 1998 , causing a current account deficit that reached $6.5 \%$ of gross domestic product (GDP) in the third quarter of that year. Subsequently, the nominalization of monetary policy in 1999 , constituted the logical consequence of the process of modernization of the conduct of monetary policy (Morandé, 2001) and its integration in the global economy system. The exchange rate band was eliminated and replaced with a flexible exchange rate system in which the value of the currency was transparently determined by the interaction of market agents while 
the Central Bank reserved the sole commitment to maintain inflation within a targeted margin. The adoption of this scheme removed a possible source of inconsistency in the design of the policy regime, as it reflects the authority's confidence in the market to independently determine the value of the national currency.

Regarding the Chilean Banking system, Fernández (2005) conducted a thorough analysis, finding evidence that banks respond asymmetrically to monetary shocks particularly in terms of the loan portfolio decisions. Traditionally, banks in Chile were classified in big and medium-sized banks, retail, and treasury banks (Jara \& Oda, 2015). Big and medium-sized banks are standard commercial banks that participate in all market segments (corporate, consumer, and mortgage credits). At the end of 2013, these banks comprised 12 institutions, seven of which were domestically owned and five that were subsidiaries of foreign banks, accounting for more than $95 \%$ of total assets. Retail banks are domestically owned, smaller in size, and focus on household finance (i.e., consumer and mortgage loans). In addition to the differences in size, market focus, and ownership structure, Chilean banks also differ in terms of international balance sheet exposure. Treasury banks hold the highest relative level of assets and liabilities overseas in comparison to other Chilean banks; the international activity of retail banks is negligible. Gajewski et al. (2019) had recently summarized the key characteristics of the Chilean banking system. It is highly heterogeneous in terms of size, business orientation, and funding structure. In October 2018, the most important reform in the Chilean banking system was approved, seeking harmonization with BASILEA III standards. Acceptance lays the ground for a possible concentration process and a significant increase in the participation of foreign banks in the near future.

Regarding Chile's economy and financial policies, the financial crisis generated with the bankruptcy of Lehman Brothers in September 2008, provoked the first step of 
the monetary policy developed by the Central Bank from then to the present day. In fact, the Chilean economy managed to overcome the crisis reasonably well. Although there was a decrease in growth, there was no internal crisis neither was there a sharp increase in unemployment nor did wages and incomes fall. Alvarez et al. (2012) analyzed the impact of the crisis concluding that liquidity crises had a negative and significant effect on cash holdings, but mainly for small firms reducing the ability of Chilean firms to adjust to optimal cash holdings, but it was medium-sized firms which had more difficulties to adjust cash holdings. However, the great dependency of the economy in the mining business (in 2018, Chile produced $28 \%$ of the world's copper) triggered a significant brake on the economy after 2014 with negative GDP quarters, due to copper pricing being far below US\$3 (see Figure 1) and fluctuations in global demand.

\section{FIGURE 1 ABOUT HERE}

As Chile has a small internal market (population is about 18 million), and great dependency on the mining business (almost 10\% of its GDP), it has generated a great dependency on the commodity international market. In recent times, the economy has only grown 1,4\% in GDP terms (2018). This low rate is still amplifying the differences in social structure, provoking social clashes. To resolve this, Chile is endeavoring to diversify its reliance on copper with other promising mining activities such as Lithium, for which it is the country with the largest reserves (Statista, 2020); however, the impact in the local economy is expected to be long term. Today, its monetary policy is seeking to maintain purchasing power and achieve the objectives of meeting the inflationary targets. According to latest OECD economic outlook (2019), economic growth is projected to strengthen gradually in the upcoming years, but still remain weaker than previously expected. The fiscal policy needs to equilibrate the social differences among the population but remain prudent to ensure the compliance of fiscal rule with inclusive 
growth reforms. The Central Bank of Chile is also considering further monetary initiatives to stimulate monetary policies with special attention being paid to their impact on the flow of credit in the economy, however its benchmark interest rate remains at a technical minimum of $0.5 \%$, which is its lowest level since 2009 and provides a limited margin for maneuver if further shocks occur.

Finally, in terms of the social structure, the Chilean society (OECD Economic Policy Reforms, 2019) indicate that the convergence rate in GDP per capita to the upper half of OECD countries is one of the most rapid in the OECD over the last decades. However, this progress came to a halt after 2013 as a consequence of the aforementioned problems, generating weak employment growth and a decline in total factor productivity growth. This has meant that in 2019 income inequality and poverty are still high which has generated social clashes. The Gini coefficient is 45.4 (lower than the median of emerging economies), but higher than advanced economies (29.7) implying a less equitable distribution of income with respect to the advanced economies.

The COVID-19 crisis will be a challenge for this economy. According to the recent Fitch Ratings Report (Martinez et al., 2020), its impact is expected to have a major effect on all LatAm economies due to their weak public finances. In the specific case of the Chilean economy, due to its past fiscal strength, fiscal packages have been implemented to broaden counter-cyclical policies, however this strength has eroded in recent years and difficulties are expected when it comes to preserving or rebuilding fiscal buffers post-crisis if further response is needed in case of future shocks.

In this paper the statistical properties of several monetary aggregates in the Chilean economy will be investigated to determine if shocks affecting them have permanent or transitory effects, with the implications that this has in terms of policy actions to be adopted by the monetary authorities. 


\section{Literature review}

The use of fractional integration models to analyze persistence of macroeconomic data has been a topic recently covered in the literature to analyze the behavior of a country. During this short literature review, we will focus on the analysis of the monetary aggregates. Barkoulas et al. (1999) tested the fractional dynamics in US monetary series using a spectral regression method and finding evidence of a fractional exponent in the differencing process of the monetary series and in their components. In a similar way, Gil-Alana (2007) examined the German monetary aggregate M1 with fractional integration, finding a strong degree of persistence, especially in the long run, with orders of integration ranging between 1.25 and 1.50. Caporale and Gil-Alana (2008), analyzed monthly seasonally unadjusted US monetary aggregates, also finding evidence of fractional orders of integration in the series examined. Barros et al. (2014), examined monetary aggregates and some other macroeconomic variables, using monthly data, and looking for persistence and mean reversion behavior. Caporale et al. (2017) studied the bilateral linkages between the central bank policy rates of the US, the Eurozone, Australia, Canada, Japan and the UK with fractionally integrated methods, finding evidence of high degrees of persistence in all cases. Thus, though the literature on long range dependence in these variables is scarce, all them find evidence of this feature across different monetary aggregates.

\section{Modelling approach}

\subsection{Fractional Integration}


Fractional integration is a time series technique that allows for a fractional degree of differentiation. Given a time series, $\mathrm{x}_{\mathrm{t}}, \mathrm{t}=1,2, \ldots$, we say that it is integrated of order $\mathrm{d}$, and denoted by $\mathrm{I}(\mathrm{d})$ if its d-differences are stationary $\mathrm{I}(0)$.

A series is $\mathrm{I}(0)$, also termed short memory, if the infinite sum of its autocovariances is finite, and within this category, we can include the white noise process, but also, other models which are weakly autocorrelated such as those based on stationary and invertible AutoRegressive Moving Average (ARMA) models.

Mathematically speaking, we say that $\mathrm{x}_{\mathrm{t}}$ is $\mathrm{I}(\mathrm{d})$ if it can be represented as:

$$
(1-L)^{d} x_{t}=u_{t}, \quad t=1,2, \ldots,
$$

where $\mathrm{L}$ is the lag-operator, i.e., $\mathrm{Lx}_{t}=\mathrm{x}_{\mathrm{t}-1}$ and $\mathrm{u}_{\mathrm{t}}$ is $\mathrm{I}(0)$. Thus, if $\mathrm{u}_{\mathrm{t}}$ is $\operatorname{ARMA}(\mathrm{p}, \mathrm{q})$, we say that $x_{t}$ is a fractionally integrated ARMA, i.e., ARFIMA(p, $\left.d, q\right)$ model. Clearly, if $d=1$ in (1) we have the classical unit root model (a random walk if $u_{t}$ is white noise), but as earlier mentioned, $\mathrm{d}$ can also be a fractional value, throughout the following Binomial expansion,

$$
(1-L)^{d}=\sum_{j=0}^{\infty}\left(\begin{array}{l}
d \\
j
\end{array}\right)(-1)^{j} L^{j}=1-d L+\frac{d(d-1)}{2} L^{2}-\ldots,
$$

which is valid for any real value $d$. Then, equation (1) can be expressed as

$$
x_{t}=d x_{t-1}-\frac{d(d-1)}{2} x_{t-2}+\ldots+u_{t}
$$

and the higher the value of $d$ is, the higher the level of association is between the observations and thus, the level of persistence in the data.

\subsection{Fractional Cointegrated VAR}

Johansen (2008) introduced a method to check for a multivariate fractional cointegration model denominated Fractionally Cointegrated Vector AutoRegressive (FCVAR), and Johansen and Nielsen $(2010,2012)$ expanded it. It is a further step from the Cointegrated 
Vector AutoRegressive model in Johansen (1996), named CVAR, and it allows for series which are integrated of order $d$ and that cointegrate with order $d-b$, with $b>0$. Following Johansen and Nielsen (2012) and Nielsen and Popiel (2018), the FCVAR model has the power to be used for stationary and nonstationary time series.

To introduce the FCVAR model, we should start first by referring to the nonfractional CVAR model. Let $Y_{t}, t=1, \ldots, T$ be a p-dimensional I(1) time series. The CVAR model is:

$$
\Delta Y_{t}=\alpha \beta^{\prime} Y_{t-1}+\sum_{i=1}^{k} \Gamma_{i} \Delta Y_{t-i}+\varepsilon_{t}=\alpha \beta^{\prime} L Y_{t}+\sum_{i=1}^{k} \Gamma_{i} \Delta L^{i} Y_{t}+\varepsilon_{t}
$$

Replacing here the difference and lag operators by $\Delta^{b}$ and $L_{b}=1-\Delta^{b}$, we obtain:

$$
\Delta^{b} Y_{t}=\alpha \beta^{\prime} L_{b} Y_{t}+\sum_{i=1}^{k} \Gamma_{i} \Delta L_{b}^{i} Y_{t}+\varepsilon_{t}
$$

which is applied to $Y_{t}=\Delta^{d-b} X_{t}$ such that

$$
\Delta^{d} X_{t}=\alpha \beta^{\prime} L_{b} \Delta^{d-b} X_{t}+\sum_{i=1}^{k} \Gamma_{i} \Delta^{b} L_{b}^{i} Y_{t}+\varepsilon_{t}
$$

where $\varepsilon_{t}$ is p-dimensional independent and identically distributed, with mean zero and covariance matrix $\Omega$. From the CVAR model we can interpret the parameters. Thus $\alpha$ and $\beta$ are $p \times r$ matrices, where $0 \leq r \leq p$. The columns of $\beta$ are the cointegrating relationships in the system, that is to say the long-run equilibria. $\Gamma_{i}$ is the parameter that governs the short-run behavior of the variables. The coefficients in $\alpha$ represent the speed of adjustment responses to deviations from the equilibria and the short-run dynamics of the system. Additionally, we can find two parameters compared with the CVAR model. The order of fractional integration of the observable time series is represented by $d$ and the level of reduction in the fractional integration order of $\beta^{\prime} X_{t}$ is represented by the parameter $b$.

Matlab computer programs for the calculation of estimators and test statistics in the FCVAR model are provided by Nielsen and Popiel (2018) ${ }^{1}$ and have been employed

\footnotetext{
${ }^{1}$ https://sites.google.com/view/mortennielsen/software?authuser=0
} 
in numerous empirical papers (Jones, Nielsen and Popiel, 2014; Baruník and Dvořáková, 2015; Maciel, 2017; Aye et al., 2017; Dolatabadi et al., 2018; Gil-Alana and Carcel, 2018; etc.).

\section{Data and empirical results}

The data series analyzed are the monetary aggregates and their components (in averages billions of Chilean pesos) provided by the Central Bank of Chile. This data is summarized in Figure 2, where selected data has been currency in circulation (C), and monetary masses (M1, M2 and M3) which are displayed in log scale. The data frequency used is monthly, with the starting date of January 1986 and the ending date in May 2019.

\section{FIGURE 2 ABOUT HERE}

The results are displayed across Tables $1-3$. In all cases, the model examined is the following one,

$$
y_{t}=\alpha+\beta t+x_{t}, \quad(1-L)^{d} x_{t}=u_{t}, \quad t=1,2, \ldots,
$$

where $y_{t}$ refers to each of the monetary aggregates, i.e., C, M1, M2 and M3; $\alpha$ and $\beta$ are unknown coefficients, referring respectively to a constant and a (linear) time trend; $\mathrm{x}_{\mathrm{t}}$ is the detrended series; and $\mathrm{u}_{\mathrm{t}}$ is an $\mathrm{I}(0)$ process that will adopt different models. Thus, in Table $1, \mathrm{u}_{\mathrm{t}}$ is supposed to be a white noise process; in Table 2 weak autocorrelation is permitted and we employ here a non-parametric approach due to Bloomfield (1973) widely used in the context of fractional integration (Gil-Alana, 2004; 2005); finally, in Table 3 and based on the monthly nature of the data, a seasonal AR(1) process of the form:

$$
u_{t}=\rho u_{t-12}+\varepsilon_{t}, \quad t=1,2, \ldots
$$

is used where $\varepsilon_{t}$ is now a white noise process. 
Across the three tables we display the estimates of $d$ in (7) under three different set-ups. First, we suppose that both $\alpha$ and $\beta$ are equal to zero a priori, implying the non existence of deterministic components. (Results are displayed in the second columns of the tables); next, we allow for an intercept, and thus, only $\beta$ is supposed to be zero (third column); finally, a linear time trend is permitted and both coefficients are freely estimated from the data (fourth column). Along with the estimates of $d$ we also report in the tables the confidence bands of the values of $d$ at the $95 \%$ level. This will permit us to test standard hypotheses like those based on $\mathrm{I}(0)$ and $\mathrm{I}(1)$ models but also other fractional alternatives. Finally, the upper part of the tables refers to the nominal values; panel ii) reports the results for the real values, while the lower panel refers to seasonally adjusted real values for the monetary aggregates.

\section{TABLE 1 - 3 ABOUT HERE}

We start presenting the results based on white noise errors, in Table 1 . The first noticeable fact is that the time trend is statistically significant in all cases, and the estimated values of $\mathrm{d}$ for this model are relatively large in all cases. In fact, evidence of mean reversion is only achieved in two cases, both referring to $\mathrm{C}$ (currency in circulation) with nominal and with real values. For M1, the unit root null hypothesis cannot be rejected in the first two panels, and in the rest of the cases (M1 with seasonally adjusted real values, and M2 and M3 in the three cases) the unit root null hypothesis is decisively rejected in favor of $d>1$. We also note that in general, the order of integration, and thus the degree of persistence seems to increase with the monetary aggregate, implying a much higher degree of persistence for M2 and M3 than for C and M1.

In comparison with the results in Gil-Alana (2007) for the German M1, while the degree of persistence in that case ranges between 1.25 and 1.50, these values in our case for Chile are only reached in real seasonally adjusted calculations, while real or nominal 
figures reveal lower degrees of persistence, with orders of integration close to 1 . Nevertheless, for M2 and M3 monetary aggregates our estimates of $\mathrm{d}$ are higher, being about 1.18 and 1.34 respectively.

If autocorrelation is permitted, in Table 2, mean reversion is achieved in a single case (M1 with real values), however not in the case of $\mathrm{C}$. Thus, the I(1) hypothesis cannot be rejected for M1 with nominal values, and for $\mathrm{C}$ and M2 with real values, and $\mathrm{d}$ is statistically higher than 1 in the rest of the cases, implying a large degree of persistence. However, the order of integration is not following now an increasing order as in the previous case with uncorrelated errors.

Finally, allowing for a seasonal AR(1) error term, in Table 3, the results are fairly similar to those reported for the white noise case. Mean reversion occurs in $\mathrm{C}$ with nominal values, the $\mathrm{I}(1)$ hypothesis cannot be rejected for $\mathrm{C}$ with real values and also for M1 with nominal and real values, and d is statistically significantly above 1 in all the other cases, observing once more an increase in the degree of integration as we increase the level in the monetary aggregate. As a robustness method, all computations were also conducted on the log-transformed data, and the results, displayed in the Appendix, are fairly similar to those reported here.

The next step is calculating the FCVAR model, proposed by Johansen and Nielsen (2012), that is, the classical CVAR model extended to fractional integration in order to test the possible existence of persistence in the spread. Considering that an overly long lag length could distort the data and lead to a decrease in the estimation power, we have followed Jones, Nielsen and Popiel (2014) using a lag value $k=3$. Also, we follow two additional elements in the specification of the FCVAR model: the deterministic components and the cointegration rank $(r)$. Firstly, we impose $d=b$ in (6), and then we allow for different degrees of integration in the FCVAR representation. Conducting LR 
tests between the two cases, the results indicate that $d$ is equal to $b$ in the first two cases (nominal and real series), while different values are reported in the case of the real seasonal series. The results are presented in Table 4 .

\section{[TABLE 4 ABOUT HERE]}

For the nominal series, the estimated value of $d$ is 0.987 , and for the real series 1.062. In both cases, $d=b$ implying $I(0)$ cointegrating errors. Thus, the results in these two group of variables should be very similar to those based on a non-fractional CVAR model (i.e., with $d=b=1$ ). For the real seasonal group of series, the test statistics reject the hypothesis of $d=b$; the estimation for $d$ is significantly higher than $1,(1.217)$ and $b$ is equal to 0.814 , implying a degree of integration for the cointegrating vector of 0.403 . Thus, the adjustment process is slower in this group of series than in the other two groups.

\section{Conclusions}

In this article we have examined the statistical structure of the monetary aggregates in Chile. For this purpose, we have used techniques based on fractional integration, which are very appropriate to determine the nature of the shocks. The first thing we observe is that a time trend is required in all series examined and the order of integration is close to 1 in all cases. Evidence of mean reversion is only found in the cases of C and M1 for some of the series, while for M2 and M3 the results clearly show persistence with orders of integration statistically higher than 1 . Thus, external shocks are expected to have a permanent effect on the Chilean economy in fiduciary money, though with a weak mean reversion effect in the M1 and Currency on circulation. Another noticeable feature in our data is the fact that there seems to be some level of correlation between the degree of persistence of the monetary series and the size of the aggregate. 
Looking at the multivariate case, by using a fractional CVAR (FCVAR), the results support the hypothesis of cointegration in the three cases; for the nominal and real series, the model imposes $\mathrm{I}(1)$ individual series and $\mathrm{I}(0)$ cointegrating errors, while for the real seasonal series, the order of integration of the individual series is about 1.2, and a long memory pattern is detected for the error term. Thus, the adjustment equilibrium process is supposed to take longer to converge in the seasonal real series than in the other two groups of nominal and real series. 


\section{References}

Alvarez R., Sagner A. and Valdivia, C. (2012) Liquidity Crises and Corporate Cash Holdings in Chile. The Developing Economies, 50 (4): 378-392 DOI: 10.1111/j.17461049.2012.00180.x

Aye, G. C., Carcel, H., Gil-Alana, L. A., Gupta, R. (2017). Does gold act as a hedge against inflation in the UK? Evidence from a fractional cointegration approach over 1257 to 2016. Resources Policy, 54, 53-57.

Barkoulas J., Baum C. and Caglayan M. (1999) "Fractional Monetary Dynamics" Applied Economics, 31(11): 1393-1400.

Barros C. P., Caporale G. M. and Gil-Alana L. A. (2014). Long Memory in Angolan Macroeconomic Series: Mean Reversion versus Explosive Behaviour. African Development Review 26 (1): 59-73

Baruník, J., Dvořáková, S. (2015). An empirical model of fractionally cointegrated daily high and low stock market prices. Economic Modelling, 45, 193-206.

Benali M., El Hafidi M., Aït Oudra M. (2006). La demande de monnaie M1 et M2 au Maroc: étude en terme de la cointégration. Revue de droit et d'économie 21-22: 343-361

Bloomfield, P. (1973) An exponential model in the spectrum of a scalar time series, Biometrika 60, 217-226.

Caporale G. M., Carcel H. and Gil-Alana L. (2017). Central bank policy rates: Are they $\begin{array}{llll}\text { cointegrated?. International } & \text { Economics } & 152: & 116-123\end{array}$ https://doi.org/10.1016/j.inteco.2017.06.001

Caporale, G. M. \& Gil-Alana, L. A. (2008) "Testing for Unit and Fractional Orders of Integration in the Trend and Seasonal Components of Us Monetary Aggregates," Empirica 35(3), 241-253.

Caporale, G., \& Gil-Alana, L. (2018). Unemployment in africa: A fractional integration approach. South African Journal of Economics, 86(1), 76-81. doi:10.1111/saje.12178

Dolatabadi, S., Narayan, P. K., Nielsen, M. Ø., Xu, K. (2018). Economic significance of commodity return forecasts from the fractionally cointegrated VAR model. Journal of Futures Markets, 38(2), 219-242.

Fernández, V. (2005). Monetary Policy and the Banking Sector in Chile. Emerging Markets Finance and Trade, 41 (3): 5-36. ISSN 1540-496X/2005

Gajewski K., Jara A., Kang Y., Mok J., Moreno D., Serwa D., (2019). International spillovers of monetary policy: Lessons from Chile, Korea, and Poland. Journal of International Money and Finance (90): 175-186. ISSN 0261-5606, https://doi.org/10.1016/j.jimonfin.2018.08.009 
Gil-Alana, L.A. (2004), The use of Bloomfield (1973) model as an approximation to ARMA processes in the context of fractional integration, Mathematical and Computer Modelling 39, 429-436.

Gil-Alana, L.A. (2007). Investigating the seasonal structure in the german economy using fractional integration with structural breaks. Studies in Economics and Finance, 24(2): 96-114. doi:http://dx.doi.org.bucm.idm.oclc.org/10.1108/10867370710756165

Gil-Alana, L.A., Carcel, H. (2018). A fractional cointegration var analysis of exchange rate dynamics. The North American Journal of Economics and Finance.

Guzmán J., (2018). Macroeconomic shocks and policy reforms: lessons from the 1999 downturn in Chile. Revista CEPAL. Naciones Unidas, Comisión Económica para América Latina y el Caribe (CEPAL).

Hassler U., Rodrigues P. M.M., Rubia A. (2014). Persistence in the banking industry: Fractional integration and breaks in memory. Journal of Empirical Finance, 29: 95-112. ISSN 0927-5398. https://doi.org/10.1016/j.jempfin.2014.03.004.

Jara A., Oda D. (2015) Agrupación de Instituciones Bancarias a Partir del Análisis de Cluster: Una Aplicación al Caso de Chile. Central Bank of Chile - Economía Chilena 17 (2): $80-102$

Johansen, S. (1996). Likelihood-based inference in cointegrated vector autoregressive models. New York, NY: Oxford University Press.

Johansen, S. (2008). A representation theory for a class of vector autoregressive models for fractional processes. Econometric Theory, 24, 651-676.

Johansen, S., Nielsen, M. Ø. (2010). Likelihood inference for a nonstationary fractional autoregressive model. Journal of Econometrics, 158, 51-66.

Johansen, S., Nielsen, M. Ø. (2012). Likelihood inference for a fractionally cointegrated vector autoregressive model. Econometrica, 80, 2667-2732.

Jones, M. E., Nielsen, M. Ø., Popiel, M. K. (2014). A fractionally cointegrated VAR analysis of economic voting and political support. Canadian Journal of Economics, 47, 1078-1130.

Jonsson G., (1999). Inflation, Money Demand, and Purchasing Power Parity in South Africa. IMF, African Department; 1999

Kinda T. (2011). Modeling Inflation in Chad. IMF WP/11/57

Kontolemis, Z. G. (2002). Money demand in the Euro Area. Where do we stand (today)?; IMF Working Paper, Wp/02/185; International Monetary Fund: Washington, D.C..

Maciel, L. (2018). Technical analysis based on high and low stock prices forecasts: Evidence for Brazil using a fractionally cointegrated VAR model. Empirical Economics, $1-28$.

Martinez T., Shetty S., Dychala C. (2020). Fitch Ratings: Coronavirus Amplifies LatAm Sovereigns' Fiscal, Rating Pressures. https://www.fitchratings.com/site/re/10121870 
Morandé L. F., (2001). A Decade of Inflation Targeting in Chile: Developments, Lessons, and Challenges. Journal Economía Chilena, Central Bank of Chile, 4: 35-62.

Nachega, J.C. (2001). A cointegration analysis of broad money demand in Cameroon; IMF Working Paper, Wp/01/26; International Monetary Fund, African Dept. Washington, D.C., 2001.

Nassar, K. (2005) Money Demand and Inflation in Madagascar. IMF Working Paper $\mathrm{WP} / 05 / 236$

Nautz D. and Scheithauer J. (2011). Monetary policy implementation and overnight rate persistence. Journal of International Money and Finance, 30 (7): 1375-1386. ISSN 02615606. https://doi.org/10.1016/j.jimonfin.2011.07.005.

Nielsen, M. Ø., Popiel, M. K. (2018). A Matlab program and user's guide for the fractionally cointegrated VAR model (Queen's Economics Department Working Paper No 1330). Ontario, Canada, K7L 3N6.

OECD (2019), OECD Economic Outlook, Volume 2019 Issue 2, No. 106, OECD Publishing, Paris, https://doi.org/10.1787/9b89401b-en.

OECD (2019), Economic Policy Reforms 2019: Going for Growth, OECD Publishing, Paris, https://doi.org/10.1787/aec5b059-en.

Serletis, A. (2007). The Demand for Money: Theoretical and Empirical Approaches (2nd Edition). Springer

STATISTA (2020), Mining in Chile. Article number did-49757-1.

STATISTA (2020), Copper. Article number did-14271-1. 
Table 1: Estimated of $d$ under the assumption of uncorrelated errors

\begin{tabular}{|c|c|c|c|}
\hline \multicolumn{4}{|c|}{ i) Nominal values } \\
\hline Series & No terms & An intercept & A linear time trend \\
\hline $\mathrm{C}$ & $0.96(0.94,1.00)$ & $0.96(0.94,0.99)$ & $0.96(0.93,0.99)^{*}$ \\
\hline M1 & $1.04(1.00,1.09)$ & $1.04(1.00,1.09)$ & $1.04(1.00,1.10)$ \\
\hline M2 & $1.22(1.17,1.28)$ & $1.21 \quad(1.16,1.28)$ & $1.23(1.18,1.29)$ \\
\hline M3 & $1.32(1.27,1.39)$ & $1.32(1.27,1.39)$ & 1.34 (1.29, 1.40) \\
\hline \multicolumn{4}{|c|}{ ii) Real values (original data) } \\
\hline Series & No terms & An intercept & A linear time trend \\
\hline $\mathrm{C}$ & $0.89(0.86,0.94)$ & $0.90 \quad(0.94,0.94)$ & $0.88(0.84,0.93)^{*}$ \\
\hline M1 & $0.98(0.94,1.05)$ & $0.98 \quad(1.00,1.05)$ & $0.98 \quad(0.93,1.05)$ \\
\hline M2 & $1.16(1.09,1.25)$ & $1.16(1.16,1.25)$ & $1.18(1.11,1.27)$ \\
\hline M3 & $1.15(1.10,1.22)$ & $1.17(1.27,1.24)$ & $1.19(1.14,1.26)$ \\
\hline \multicolumn{4}{|c|}{ i) Real values (seasonal adjusted) } \\
\hline Series & No terms & An intercept & A linear time trend \\
\hline $\mathrm{C}$ & $1.12(1.07,1.18)$ & $1.21(1.17,1.27)$ & $1.23 \quad(1.18,1.27)$ \\
\hline M1 & $1.17(1.12,1.22)$ & $1.15(1.11,1.20)$ & $1.17(1.13,1.22)$ \\
\hline M2 & $1.22(1.16,1.30)$ & $1.24(1.18,1.32)$ & $1.26(1.20,1.33)$ \\
\hline M3 & $1.17(1.12,1.23)$ & $1.22(1.17,1.28)$ & $1.24(1.19,1.30)$ \\
\hline
\end{tabular}

Bold, significant models according to the deterministic terms. *: evidence of mean reversión $(\mathrm{d}<1)$. 
Table 2: Estimated of $\mathbf{d}$ under the assumption of autocorrelated Bloomfield errors

\begin{tabular}{|c|c|c|c|}
\hline \multicolumn{4}{|c|}{ i) Nominal values } \\
\hline Series & No terms & An intercept & A linear time trend \\
\hline $\mathrm{C}$ & $1.12(1.07,1.18)$ & $1.12(1.08,1.18)$ & $1.14(1.09,1.20)$ \\
\hline M1 & $0.99(0.95,1.04)$ & $1.00(0.95,1.04)$ & $0.99(0.95,1.05)$ \\
\hline M2 & $1.14(1.09,1.19)$ & $1.14(1.09,1.20)$ & $1.16(1.11,1.22)$ \\
\hline M3 & $1.29(1.23,1.38)$ & $1.29(1.23,1.38)$ & $1.32(1.26,1.40)$ \\
\hline \multicolumn{4}{|c|}{ ii) Real values (original data) } \\
\hline Series & No terms & An intercept & A linear time trend \\
\hline $\mathrm{C}$ & $0.98 \quad(0.92,1.05)$ & $1.01 \quad(0.96,1.07)$ & $1.01(0.95,1.09)$ \\
\hline M1 & $0.91 \quad(0.86,0.96)$ & $0.90(0.86,0.95)$ & $0.88(0.83,0.94) *$ \\
\hline M2 & $1.01(0.95,1.07)$ & $1.02(0.98,1.07)$ & $1.02(0.97,1.09)$ \\
\hline M3 & $1.12(1.06,1.21)$ & $1.11(1.06,1.18)$ & $1.13(1.07,1.21)$ \\
\hline \multicolumn{4}{|c|}{ i) Real values (seasonal adjusted) } \\
\hline Series & No terms & An intercept & A linear time trend \\
\hline $\mathrm{C}$ & $1.15(1.08,1.26)$ & $1.24(1.18,1.34)$ & $1.27(1.21,1.35)$ \\
\hline M1 & $1.30(1.21,1.45)$ & $1.34(1.24,1.48)$ & $1.34(1.26,1.47)$ \\
\hline M2 & $1.14(1.08,1.24)$ & $1.18(1.11,1.26)$ & $1.20(1.14,1.29)$ \\
\hline M3 & $1.17(1.11,1.26)$ & $1.17(1.12,1.24)$ & $1.20(1.14,1.28)$ \\
\hline
\end{tabular}

Bold, significant models according to the deterministic terms. *: evidence of mean reversión $(\mathrm{d}<1)$. 
Table 3: Estimated of $\mathbf{d}$ under the assumption of seaonally autocorrelated errors

\begin{tabular}{|c|c|c|c|}
\hline \multicolumn{4}{|c|}{ i) Nominal values } \\
\hline Series & No terms & An intercept & A linear time trend \\
\hline $\mathrm{C}$ & $0.93(0.89,0.99)$ & $0.92(0.88,0.97)$ & $0.91(0.86,0.97)^{*}$ \\
\hline M1 & $1.04(0.99,1.11)$ & $1.04(0.99,1.12)$ & $1.04(0.98,1.12)$ \\
\hline M2 & $1.21(1.14,1.30)$ & $1.20(1.15,1.29)$ & $1.22(1.16,1.30)$ \\
\hline M3 & $1.32(1.27,1.40)$ & $1.32(1.26,1.40)$ & $1.34(1.28,1.41)$ \\
\hline \multicolumn{4}{|c|}{ ii) Real values (original data) } \\
\hline Series & No terms & An intercept & A linear time trend \\
\hline $\mathrm{C}$ & $0.97 \quad(0.87,1.05)$ & $0.94(0.88,1.02)$ & $0.94(0.88,1.02)$ \\
\hline M1 & $1.04(0.98,1.12)$ & $1.02(0.96,1.09)$ & $1.02(0.96,1.10)$ \\
\hline M2 & $1.17(1.09,1.29)$ & $1.16(1.09,1.27)$ & $1.17(1.10,1.27)$ \\
\hline M3 & $1.15(1.03,1.22)$ & $1.16(1.10,1.25)$ & $1.18(1.12,1.26)$ \\
\hline \multicolumn{4}{|c|}{ i) Real values (seasonal adjusted) } \\
\hline Series & No terms & An intercept & A linear time trend \\
\hline $\mathrm{C}$ & $1.12(1.07,1.18)$ & $1.23(1.19,1.29)$ & $1.25(1.21,1.30)$ \\
\hline M1 & $1.17(1.12,1.22)$ & $1.15(1.12,1.21)$ & $1.17(1.13,1.22)$ \\
\hline M2 & $1.21(1.16,1.30)$ & $1.24(1.18,1.32)$ & $1.26(1.20,1.33)$ \\
\hline M3 & $1.17(1.11,1.22)$ & $1.22(1.19,1.28)$ & $1.25(1.21,1.31)$ \\
\hline
\end{tabular}

Bold, significant models according to the deterministic terms. *: evidence of mean reversión $(\mathrm{d}<1)$. 
Table 4: Results based on the FCVAR model

\begin{tabular}{|c|c|c|c|c|c|c|c|c|c|}
\hline Series & $\mathrm{d}(=\mathrm{b})$ & $\mu_{1}$ & $\mu_{2}$ & $\mu_{3}$ & $\mu_{4}$ & $\Gamma_{1}$ & $\Gamma_{2}$ & $\Gamma_{3}$ & $\Gamma_{4}$ \\
\hline Nominal & $\begin{array}{c}0.987 \\
(0.048)\end{array}$ & 337.378 & 909.278 & 3316.575 & 5419.982 & -0.013 & -0.136 & -0.328 & -0.514 \\
\hline Real & $\begin{array}{c}1.062 \\
(0.035)\end{array}$ & 67.0126 & 234.726 & 681.068 & 1202.120 & 0.010 & 0.074 & 0.147 & 0.215 \\
\hline Series & $d(\neq b)$ & $\mu_{1}$ & $\mu_{2}$ & $\mu_{3}$ & $\mu_{4}$ & $\Gamma_{1}$ & $\Gamma_{2}$ & $\Gamma_{3}$ & $\Gamma_{4}$ \\
\hline Real (S) & $\begin{array}{c}\mathrm{d}=1.217 \\
(0.055) \\
\mathrm{b}=0.814 \\
(0.201)\end{array}$ & 308.827 & 829.563 & 3254.891 & 5364.976 & -0.007 & -0.111 & -0.316 & -0.665 \\
\hline
\end{tabular}


FIGURE 1. Chilean GDP evolution and copper price

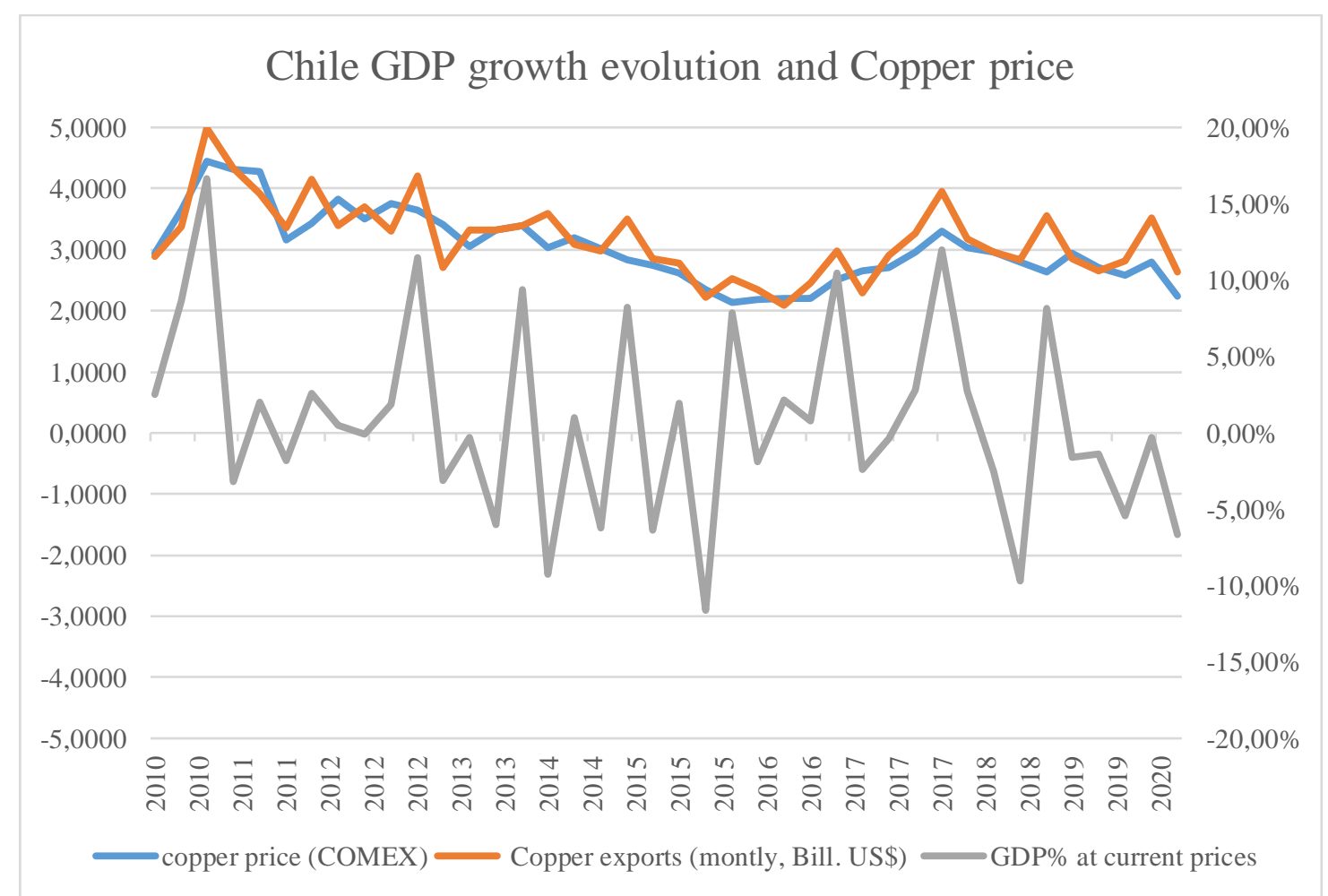

FIGURE 2. Monetary aggregates in Chile

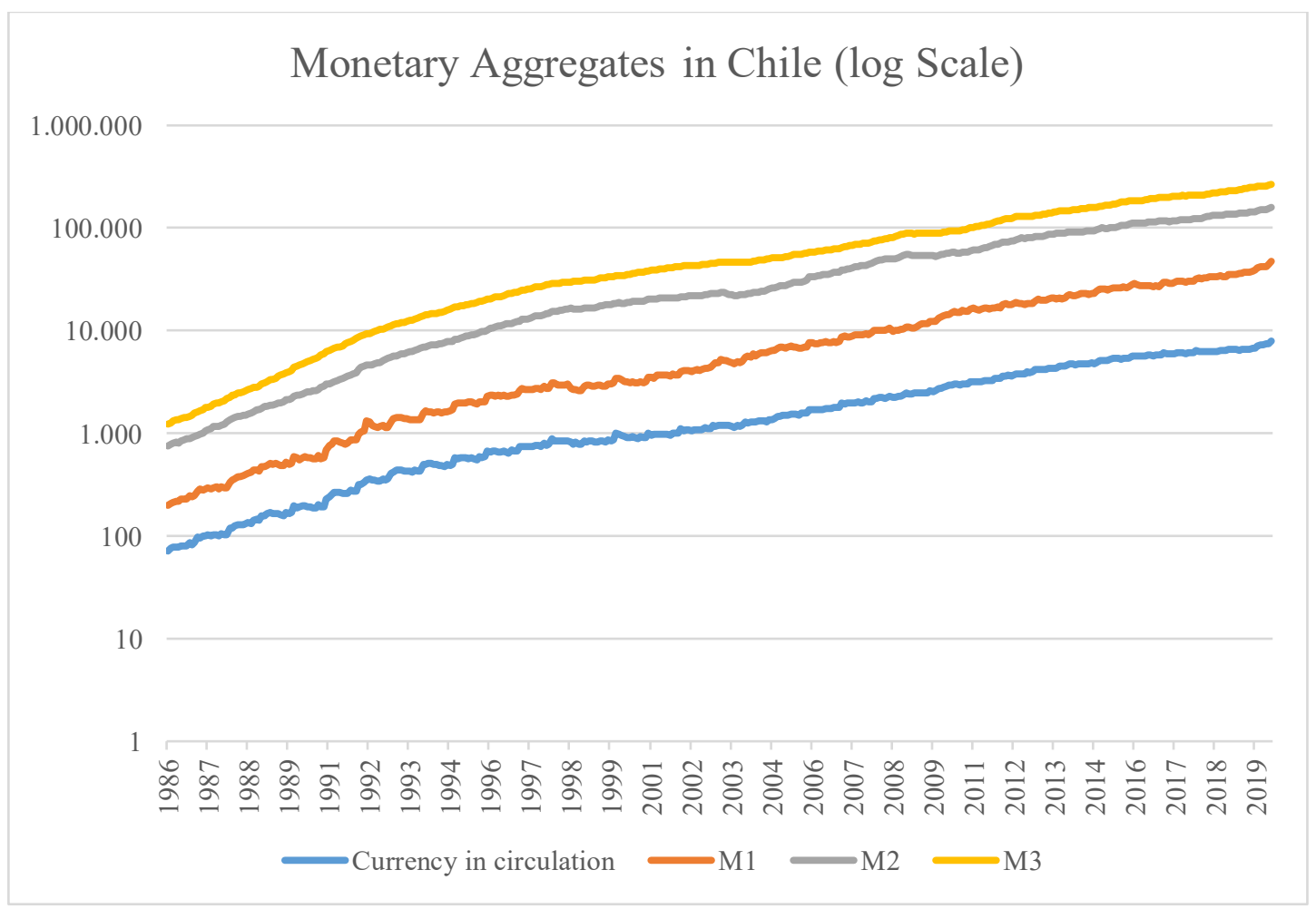




\section{APPENDIX}

Table A1: Estimated of $d$ under the assumption of uncorrelated errors

\begin{tabular}{|c|c|c|c|}
\hline \multicolumn{4}{|c|}{ i) Nominal values } \\
\hline Series (logged) & No terms & An intercept & A linear time trend \\
\hline $\mathrm{C}$ & $0.99(0.93,1.07)$ & $0.81 \quad(0.76,0.89)$ & $0.87(0.83,0.92)^{*}$ \\
\hline M1 & $0.99(0.93,1.07)$ & $0.93(0.84,1.04)$ & $0.95(0.89,1.03)$ \\
\hline M2 & $0.99(0.93,1.07)$ & $130 \quad(1.26,1.37)$ & $1.24(1.20,1.30)$ \\
\hline M3 & $0.99(0.93,1.07)$ & $1.38(1.33,1.43)$ & $1.30(1.26,1.35)$ \\
\hline \multicolumn{4}{|c|}{ ii) Real values (original data) } \\
\hline Series (logged) & No terms & An intercept & A linear time trend \\
\hline $\mathrm{C}$ & $0.99(0.93,1.07)$ & $0.78 \quad(0.74,0.84)$ & $0.75(0.68,0.83)^{*}$ \\
\hline M1 & $0.99(0.93,1.07)$ & $0.92(0.83,1.04)$ & $0.92(0.82,1.04)$ \\
\hline M2 & $0.99(0.93,1.07)$ & $1.16(1.07,1.26)$ & $1.14(1.06,1.23)$ \\
\hline M3 & $0.99(0.93,1.07)$ & $1.15(1.08,1.23)$ & $1.11(1.05,1.18)$ \\
\hline \multicolumn{4}{|c|}{ i) Real values (seasonal adjusted) } \\
\hline Series (logged) & No terms & An intercept & A linear time trend \\
\hline $\mathrm{C}$ & $0.99(0.93,1.07)$ & $1.22(1.14,1.32)$ & $1.22(1.14,1.31)$ \\
\hline M1 & $0.99(0.93,1.07)$ & $1.02(0.95,1.11)$ & $1.02(0.95,1.11)$ \\
\hline M2 & $0.99 \quad(0.93,1.07)$ & $1.19(1.12,1.26)$ & $1.16(1.10,1.23)$ \\
\hline M3 & $0.99 \quad(0.93,1.07)$ & $1.18(1.13,1.24)$ & $1.13(1.09,1.20)$ \\
\hline
\end{tabular}

Bold, significant models according to the deterministic terms. *: evidence of mean reversión $(\mathrm{d}<1)$. 
Table A2 Estimated of $\mathrm{d}$ under the assumption of autocorrelated Bloomfield errors

\begin{tabular}{|c|c|c|c|}
\hline \multicolumn{4}{|c|}{ i) Nominal values } \\
\hline Series (logged) & No terms & An intercept & A linear time trend \\
\hline $\mathrm{C}$ & $0.97 \quad(0.87,1.11)$ & $0.98(0.85,1.15)$ & $0.99 \quad(0.92,1.10)$ \\
\hline M1 & $0.97(0.88,1.12)$ & $0.74 \quad(0.70,0.84)$ & $0.84(0.78,0.94)^{*}$ \\
\hline M2 & $0.98 \quad(0.89,1.11)$ & $1.30(1.23,1.38)$ & $1.22(1.17,1.29)$ \\
\hline M3 & $0.98(0.88,1.11)$ & $1.43(1.37,1.52)$ & $1.33(1.28,1.39)$ \\
\hline \multicolumn{4}{|c|}{ ii) Real values (original data) } \\
\hline Series (logged) & No terms & An intercept & A linear time trend \\
\hline $\mathrm{C}$ & $0.97(0.87,1.09)$ & $0.80 \quad(0.75,0.89)$ & $0.71(0.60,0.85)^{*}$ \\
\hline M1 & $0.97(0.88,1.09)$ & $0.73(0.69,0.78)$ & $0.56(0.47,0.69)^{*}$ \\
\hline M2 & $0.97(0.88,1.09)$ & $0.94(0.85,1.06)$ & $0.96 \quad(0.88,1.06)$ \\
\hline M3 & $0.98 \quad(0.87,1.11)$ & $1.02(0.91,1.14)$ & $1.02(0.96,1.08)$ \\
\hline \multicolumn{4}{|c|}{ i) Real values (seasonal adjusted) } \\
\hline Series & No terms & An intercept & A linear time trend \\
\hline $\mathrm{C}$ & $0.98 \quad(0.87,1.10)$ & $1.07(0.95,1.23)$ & $1.07 \quad(0.95,1.20)$ \\
\hline M1 & $0.97(0.87,1.11)$ & $0.95(0.86,1.12)$ & $0.96(0.84,1.10)$ \\
\hline M2 & $0.97 \quad(0.88,1.10)$ & $1.18 \quad(1.08,1.28)$ & $1.14(1.05,1.24)$ \\
\hline M3 & $0.98 \quad(0.87,1.12)$ & $1.23(1.16,1.32)$ & $1.14(1.10,1.23)$ \\
\hline
\end{tabular}

Bold, significant models according to the deterministic terms. *: evidence of mean reversión $(\mathrm{d}<1)$. 
Table A3: Estimated of $d$ under the assumption of seaonally autocorrelated errors

\begin{tabular}{|c|c|c|c|}
\hline \multicolumn{4}{|c|}{ i) Nominal values } \\
\hline Series (logged) & No terms & An intercept & A linear time trend \\
\hline $\mathrm{C}$ & $0.99(0.92,1.07)$ & $1.05(0.97,1.14)$ & $1.04(0.97,1.12)$ \\
\hline M1 & $0.99(0.92,1.07)$ & $0.96(0.87,1.07)$ & $0.97 \quad(0.89,1.06)$ \\
\hline M2 & $0.99(0.91,1.07)$ & $1.26(1.20,1.34)$ & $1.22(1.16,1.28)$ \\
\hline M3 & $0.99(0.91,1.07)$ & $1.32(1.27,1.39)$ & $1.26(1.23,1.32)$ \\
\hline \multicolumn{4}{|c|}{ ii) Real values (original data) } \\
\hline Series & No terms & An intercept & A linear time trend \\
\hline $\mathrm{C}$ & $0.99(0.92,1.07)$ & $1.07(0.98,1.17)$ & $1.07 \quad(0.98,1.17)$ \\
\hline M1 & $0.99(0.92,1.07)$ & $1.01(0.92,1.12)$ & $1.01(0.92,1.12)$ \\
\hline M2 & $0.99(0.91,1.07)$ & $1.12(1.04,1.22)$ & $1.11(1.03,1.20)$ \\
\hline M3 & $0.99(0.91,1.07)$ & $1.08(0.99,1.17)$ & $1.06(1.00,1.14)$ \\
\hline \multicolumn{4}{|c|}{ i) Real values (seasonal adjusted) } \\
\hline Series & No terms & An intercept & A linear time trend \\
\hline $\mathrm{C}$ & $0.99(0.92,1.07)$ & $1.22(1.14,1.31)$ & $1.21(1.14,1.30)$ \\
\hline M1 & $1.00(0.93,1.07)$ & $1.02(0.95,1.11)$ & $1.02(0.95,1.11)$ \\
\hline M2 & $0.99(0.91,1.07)$ & $1.20(1.14,1.27)$ & $1.18(1.11,1.24)$ \\
\hline M3 & $0.99(0.91,1.06)$ & $1.22(1.17,1.28)$ & $1.06(1.12,1.22)$ \\
\hline
\end{tabular}

Bold, significant models according to the deterministic terms. *: evidence of mean reversión $(\mathrm{d}<1)$. 